\title{
Augmentative and Alternative Communication for Individuals with Autism Spectrum Disorder and Intellectual Disability
}

\author{
Jeff Sigafoos • Mark F. O'Reilly • Giulio E. Lancioni • \\ Dean Sutherland
}

Published online: 9 January 2014

(C) Springer International Publishing AG 2014

Opinion Statement Many individuals with autism spectrum disorder and intellectual disability are candidates for augmentative and alternative communication (AAC). We review two current trends in AAC research involving persons with ASD and intellectual disability. The first trend is the use of smartphone and tablet devices in AAC interventions. The second trend is the direct comparison of the relative efficacy of differing AAC options, for example comparing the use of manual signs versus picture-based communication systems versus speech-generating devices. Studies in the first group suggest that this new technology can be effectively used in AAC intervention. Studies in the latter group have found differences in how quickly some individuals have learned to use different options and differences in preference for the various options. These research trends suggest a possible

\footnotetext{
J. Sigafoos $(\bowtie)$

School of Educational Psychology,

Victoria University of Wellington,

PO Box 17-310, Donald Street, Karori,

Wellington 6012, New Zealand

e-mail: jeff.sigafoos@vuw.ac.nz

M. F. O'Reilly

Department of Special Education and Meadows Center for Preventing Educational Risk,

The University of Texas at Austin, Austin, TX 78712, USA

e-mail: markoreilly@austin.utexas.edu

G. E. Lancioni

Department of Neuroscience and Sense Organs,

University of Bari, Via Quintino Sella 268, 70100 Bari, Italy

e-mail: giulio.lancioni@uniba.it

D. Sutherland

School of Health Sciences, College of Education,

University of Canterbury, Christchurch 8140, New Zealand

e-mail: dean.sutherland@canterbury.ac.nz
}

new direction for AAC intervention that incorporates aspects of self-determination.

Keywords Aided communication · Augmentative and alternative communication - Autism spectrum disorder . Developmental disorders · Intellectual disability · Picture exchange $\cdot$ Manual signs $\cdot$ Self-determination .

Speech-generating devices · Unaided communication

\section{Introduction}

Augmentative and alternative communication (AAC) refers to an area of research and clinical specialization that spans several disciplines, including: (a) assistive technology, (b) psychology, (c) rehabilitation, (d) special education, and (e) speech-language pathology. AAC research has covered a wide range of topics; from developing new and more effective methods of implementing AAC, to investigating the effects of AAC use, to evaluating innovative assistive communication technologies [1-5]. Clinical practice in AAC is largely concerned with enabling people with limited speech and language to communicate using one or more alternatives to speech $[1,2,4]$. AAC systems are also often used to augment unintelligible speech $[1,4]$.

A range of non-speech communication modes have been evaluated in AAC research and implemented in clinical practice. Specific modes within this range have been classified as either unaided or aided [1]. Unaided modes include the use of gestures and manual signs. Such modes are considered unaided because communication with them does not require any external materials or equipment. Unaided AAC is considered for individuals with sufficient motor control to produce the required gestures/manual signs and when communicating with listeners who can interpret the person's gestures/manual signs. Aided AAC, in contrast, requires external materials or 
equipment. For example the person might use an alphabet board to spell out a message or select graphic symbols (e.g., line drawings or photographs) from a picture board. Another type of aided AAC system is the use of electronic speechgenerating devices [1]. Aided AAC may be indicated when the person lacks sufficient motor control for using gestures and manual signs or when the person must communicate with listeners who do not understand sign language.

AAC is indicated for individuals who present with severe communication impairment or complex communication needs. The term severe communication impairment is used in situations where the person's speech is too limited and/or too unintelligible to provide an effective means of communication [1]. Severe communication impairment is prevalent among individuals with autism spectrum disorder (ASD) and intellectual disability [6]. For such persons, a critical part of the AAC process is to design and implement evidence-based interventions. It is generally not enough to simply provide the person with an AAC system. Instead, there is typically a need for systematic, and often intensive, intervention to ensure the person learns how to use AAC for functional communication. In light of this need, the aim of this paper is to review two current and major research trends related to designing and implementing effective AAC intervention for individuals with ASD and intellectual disability and severe communication impairment. A review of this type is intended to highlight the major emerging research trends in the field and advance evidence-based practice with respect to the provision of AAC intervention to individuals with ASD and intellectual disability and severe communication impairment.

\section{Autism Spectrum Disorder}

ASD is a neurodevelopmental disorder associated with persistent deficits in social communication and social interaction, restricted interests, and repetitive behavior [7]. The prevalence of ASD has increased significantly over the past 20 years, owing in part to a broader definition and improved diagnostic practices [8]. Current prevalence is estimated at one in about every 88 children and it is four to five times more common in boys than girls [9]. There is no known cause, but genetic factors appear to be significant [10]. A significant percentage of individuals with ASD also have severe intellectual disability and severe communication impairment [7, 9].

The communication abilities of individuals with ASD can vary from quite good speech, but perhaps odd and unusual intonation patterns, to highly repetitive/perseverative speech, to cases of severe communication impairment meaning that the person develops very little or no speech. The latter condition is generally found only among individuals with ASD who would also be assessed as functioning in the severe range of intellectual disability. For the purpose of the present paper, our target population is primarily individuals who have severe communication impairment associated with ASD and/or intellectual disability. While such individuals might learn to speak with intensive early intervention [11], approximately 25 to $30 \%$ of these individuals fail to develop sufficient speech to meet their every day communication needs even with intensive intervention [6]. There is general consensus that individuals with ASD and severe communication impairment are candidates for AAC intervention [11, 12]. There is now extensive evidence to support and guide the use of AAC with individuals with ASD and/or intellectual disability who also have severe communication impairment [11, 12].

\section{Current Trends in AAC Intervention for Persons with ASD}

Since the last major survey into the use of AAC for individuals with ASD [12], two main developments have occurred. First, new technologies (mainly the Apple iPod ${ }^{\circledR} / \mathrm{iPad}^{\circledR}$ and compatible applications) have emerged. Second, a number of studies have investigated the comparative suitability of a range of AAC options for individuals with ASD.

\section{Technological Developments}

A major recent technological advance in the field has been the development of specialized speech-generating software applications (e.g., Proloquo2Go ${ }^{\mathrm{TM}}$; [13]) that can be used with smartphone and tablet devices/technology (e.g., Apple iPod Touch $^{\circledR}$ and Apple iPad $\left.{ }^{\circledR}\right)$. With such software applications, an iPod Touch $^{\circledR}$ or $\mathrm{iPad}^{\circledR}$ can be used as an aided AAC (speech-generating) device. Specifically, the software enables the device to be programmed so that tapping or lightly touching screen icons (e.g., line drawings or photographs) produces corresponding synthesized speech output. Tapping a line drawing of a glass of water, for example, could produce a correspondingly relevant phrase (e.g., "I am thirsty and would like a drink of water please."). Mirenda [14] noted several potential advantages of this new technology with respect to its use in AAC interventions for individuals with ASD. Specifically, such systems have the potential advantages of having (a) a large set of icons available in the software program, (b) high-quality synthesized voice output, (c) portability due to the relatively small size and light weight of such devices, and (d) relatively low cost (approximately \$US189.00 for the software plus another \$US500.00 for an $\left.\mathrm{iPad}^{\circledR}\right)$. Such systems might also be appealing due to ease of use, ubiquity, and social desirability. Given that such devices are more costly and more complex to operate than a low-tech picture exchange system, for example, an important question is whether individuals with ASD and other developmental 
disorders are capable of learning, and interested in using, such devices for communication purposes.

A number of recent studies [15•, 16•, 17•, 18•, 19••, 20•] have addressed this question by evaluating the effectiveness of intervention procedures aimed at teaching individuals with ASD and other developmental disorders to use the aforementioned aided AAC systems (i.e., $\operatorname{iPod}^{\circledR} / \mathrm{iPad}^{\circledR}$ and Proloquo $2 \mathrm{Go}^{\mathrm{TM}}$ software). The evaluation approach in these studies generally involved the use of single-case experimental designs [21]. Such designs are capable of demonstrating convincingly whether or not the intervention was in fact responsible for changes in one or more dependent variables (e.g., increase in correct use of the communication device). For example, Sigafoos et al. [18•] evaluated a set of instructional procedures that were intended to teach two boys with ASD to request the continuation of toy play. The boys were aged 4 and 5 years and had estimated expressive language ages of less than 2 years. The target response was to select a TOY PLAY symbol from the $\mathrm{iPad}^{\circledR}$ screen when toy play was briefly interrupted. When a child tapped the symbol, the iPad ${ }^{\circledR}$ was programmed to produce a relevant phrase via its synthetic speech output function (i.e., "I would like to play with a toy.") via the Proloquo2Go ${ }^{\mathrm{TM}}$ software [13]. The effects of intervention were evaluated in a multiple-baseline across participants design [21]. During an initial baseline phase, the children had the AAC system, but were never prompted to use it when toy play was interrupted. Intervention was then introduced to each child in a staggered (delayed) fashion. The intervention procedures involved allowing the child to select a preferred toy and play with it for about $60 \mathrm{~s}$. Toy play was then briefly interrupted for $10 \mathrm{~s}$ and the child was prompted to tap the symbol on the $\mathrm{Pad}^{\circledR}$ using the least amount of physical guidance necessary. Once the symbol had been tapped and the speech output occurred, the toy was returned and the child was allowed to continue playing. The return of toy play was intended to function as positive (and natural) reinforcement for selecting the symbol. Thus use of the $\mathrm{PPad}^{\circledR}$ was taught as a communicative request. With intervention, both boys learned to use the $\mathrm{iPad}^{\circledR}$-based speech-generating device to request the continuation of toy play. The boys maintained this skill without prompting and generalized their newly taught requesting skills to other preferred objects. Acquisition of iPad $^{\circledR}$-based requesting was associated with a decrease in aggressive behavior (i.e., hitting the trainer) for one of the boys. The other boy did not engage in any aggressive behavior during the study.

Overall these findings suggested that application of wellestablished instructional procedures [22] were effective in teaching the boys to use this new technology for functional communication. This finding is consistent with the overall positive results of the other studies that have sought to teach individuals with ASD and other developmental disorders to use iPods ${ }^{\circledR}$ or iPads ${ }^{\circledR}$ (with Proloquo2 Go ${ }^{\mathrm{TM}}$ software) as an
AAC system $[15 \bullet, 16 \bullet, 17 \bullet, 19 \bullet \bullet, 20 \bullet]$. Most of these studies focused on teaching an initial requesting function (e.g., requesting access to preferred objects), but other studies have taught picture naming [16•] and social communication, such as greeting others, saying thank you, and answering questions [20•]. Overall the collective results of these studies suggest that individuals with ASD and other developmental disorders who have limited or no speech can be successfully taught to use this new (e.g., iPod Touch ${ }^{\circledR} / \mathrm{iPad}^{\circledR}$ ) technology for communication purposes. However, teaching individuals to use this new technology may require careful implementation of well-established instructional procedures [22]. The fact that the individuals in these studies have generally learned to operate the technology to perform the targeted communication skills fairly quickly (generally within 1-2 hours of intervention) suggests that this new technology represents a viable and easy to learn method of communication that may be well suited to individuals with ASD and other developmental disorders who have severe communication impairment. However, the range of communication skills that have been taught in the studies to date has been limited to requesting, naming, and a few social communication responses. An obvious direction for future research would be to develop effective procedures for teaching individuals to use this type of technology for a wider range of communication purposes.

\section{Comparing the Suitability of AAC Options}

Mirenda [23] noted that three main AAC options or modes have been evaluated for use with individuals with ASD and severe communication impairment. These are (a) manual signs, (b) picture-exchange, and (c) speech-generating devices. With the manual sign option, individuals are taught to produce gestures, such as the manual signs for DRINK and TOY. These signs are intended to be equivalent to speaking a word or phrase (e.g., I would like a drink please. or I would like to play with that toy.). With the picture-exchange option, individuals are often first taught to select a photograph or line drawing representing some object or concept (e.g., a line drawing of a cup or a photograph of a child playing with a toy) and hand it to a listener. Handing the photograph or line drawing to the listener is intended to be equivalent to speaking a corresponding word or phrase (e.g., I would like a drink please. or I would like to play with that toy.). Bondy and Frost [24] have developed a manualized approach for teaching this type of picture-exchange communication, referred to as the Picture Exchange Communication System (PECS). Use of a speech-generating device is often similar to using picture exchange, except that when the individual selects an icon (e.g., photograph or line drawing) from the display of the speech-generating device, relevant speech output is produced. 
The speech output might be either digitized or synthesized depending on the device and software.

There has been considerable debate regarding which of these three AAC options is best able to meet the communication needs of individuals with ASD and other developmental disorders [23, 25]. There are a number of research questions that might be asked, such as (a) which of these options is best suited to the learning and behavioral characteristics of individuals with ASD, (b) which option is easiest to learn, (c) which systems are maintained and generalize better, and (d) which option would be most effective across listeners and contexts? It has been argued, for example, that picture exchange might be easier to learn because selecting the correct line drawing or photograph from an array involves recognition memory, whereas producing the correct manual sign requires recall memory [26, 27]. In addition, line drawings and photographs could be seen as perhaps easier to learn than manual signs if the drawings/photographs are highly iconic, that is if the drawings or photographs look very much like the objects/ vocabulary that they are supposed to represent [28]. On the other hand, use of manual signs does not require shifting one's attention away from the communicative context, as is the case when one is required to select a line drawing or photograph from an array. In addition, each manual sign involves a unique topography, whereas using picture exchange or a speechgenerating device involves the same topography (i.e., handing over, pointing to, or touching the line drawing/photograph). These differences in attentional demands and response topographies might make it easier to learn to use manual signs than picture exchange or speech-generating devices [25].

While each of these three AAC options has been successfully taught to individuals with ASD [26, 29-31], several recent studies have sought to compare the relative efficacy

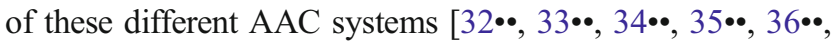
$37 \bullet \bullet, 38 \bullet, 39 \bullet \bullet$. For example, Boesch et al. [32••] compared acquisition of requesting skills with picture-exchange versus a speech-generating device in three children with ASD who had little or no speech. They found no differences in how quickly the children learned to use these two systems to make requests. They concluded that both options are equally effective and comparable in terms of ease of acquisition. Similar findings have been reported in other studies that have compared the acquisition of picture exchange systems versus speechgenerating devices $[33 \bullet \bullet, 36 \bullet \cdot]$.

Other studies, however, have reported differential performance across AAC options. Flores et al. [34••], for example, compared requesting performance of five children with developmental disorders with a picture-based communication system versus an $\mathrm{iPad}^{\circledR}$-based speech-generating device. They found that communication either increased when the children used the $\mathrm{iPad}^{\circledR}$-based speech-generating device or remained comparable to the level of performance observed with the picture-based system. Lorah et al. [35••] reported differences in how quickly five preschoolers with ASD reached mastery criterion with a picture-exchange versus an iPad ${ }^{\circledR}$-based speech-generating device. Specifically, three children reached mastery with the $\mathrm{iPad}^{\circledR}$ more quickly than with pictureexchange, but the other two children learned to use the picture-exchange system more quickly. These findings suggest that the time children with ASD require for mastering different AAC options might be related more to their individual characteristics than to differences in the level of difficulty posed by those options. Interestingly, four of the five children in the Lorah et al. study showed a preference for using the $i \mathrm{Pad}^{\circledR}$-based speech-generating device.

In line with the findings reported by Lorah et al. [35••], van

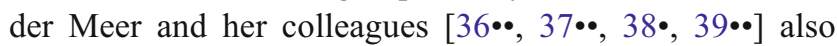
reported differing acquisition rates and preference patterns. In the first of these studies [36•*], four children with developmental disorders were taught to request snacks or toys using three AAC options: (a) manual signs, (b) picture exchange, and (c) an Apple iPod Touch ${ }^{\circledR}$ with Proloquo2 $\mathrm{Go}^{\mathrm{TM}}$ software. During and after intervention, the children were also provided with opportunities to choose among the three options to assess preference. The results for acquisition were that two children learned all three options in comparable amounts of time. The other two children learned to use picture exchange and the speech-generating device, but did not reach acquisition with the manual sign option. From the preference assessments, three of the four children most often chose the speechgenerating device (i.e., 61 to $100 \%$ of the opportunities). The other child appeared to prefer using picture exchange as he chose it on $56 \%$ of the opportunities.

Overall, the results of these comparative studies suggest that while some children are likely to learn one option more quickly and easily than others, there were no consistent differences with respect to which option was learned more quickly. In addition, the extent of performance differences across AAC options was not always very large. Indeed, most children in these studies eventually learned each of the options that were being taught and did so within a comparable period of time. This suggests that speed of acquisition might not be the most critical variable with respect to selecting AAC options for any given individual. A more consistent finding was that most children have shown a preference for using one of the AAC options that were taught.

The overall findings from these comparison studies suggest a possible new approach for selecting AAC options for individuals with ASD and other developmental disorders. Specifically, this approach would involve a three-stage process involving: (a) teaching the person to use multiple AAC options, (b) providing choice making opportunities to assess which option the person prefers to use, and (c) continuing intervention with the most preferred option. This approach could be seen as one way to incorporate aspects of selfdetermination into AAC interventions for individuals with 
ASD and other developmental disorders. Self-determination is viewed as being important in its own right, but providing such opportunity for choice and control might also increase the efficacy of intervention as noted by van der Meer and colleagues $[39 \bullet \bullet, 40]$. However, it is important to note that there is not yet sufficient data to make the claim that using a preferred $\mathrm{AAC}$ options improves outcomes from AAC intervention. The impact on preference for different AAC options on various intervention outcomes (e.g., speed of acquisition, generalization, and maintenance) would be an obvious area for future research.

\section{Summary and Conclusion}

Two current trends in AAC research for individuals with ASD and/or intellectual disability who also have severe communication impairment are (a) the use of emerging smartphone and tablet devices as speech-generating devices, and (b) comparisons of different AAC options in terms of acquisition and preference. Studies on the use of smartphone and tablet devices have mainly focused on teaching individuals to use iPods ${ }^{\circledR}$ or iPads ${ }^{\circledR}$ to make requests for preferred objects, although academic (i.e., picture naming) and social communication (e.g., making a greeting, answering questions) skills have also been taught. The results to date have been promising and suggest that individuals with ASD and other developmental disorders can learn to use this technology for communication purposes using well-established instructional strategies. Additional research is needed to investigate how this technology might be optimally used to enhance the communication and social functioning of individuals with ASD and/or intellectual disabilities and severe communication impairment.

Studies comparing different AAC options have mainly focused on comparing picture-exchange systems to the use of speech-generating devices, although a few studies have also compared manual signing to both picture-exchange systems and speech-generating devices. While there have been some differences in acquisition rates with these different options, there does not appear to be any consistent advantage for any particular AAC option. Studies that have included preference assessment have found that most participants show a preference for using one of the options they have been taught to use. The preferred option has varied across individuals. The finding that most participants showed a preference suggest that people with ASD and/or intellectual disability might be able to self-determine which of several AAC options should be incorporated into their AAC intervention.

Acknowledgments Completion of this work was supported by a grant from the New Zealand Government through the Marsden Fund Council, administered by the Royal Society of New Zealand; and by Victoria
University of Wellington, The University of Canterbury, and The New Zealand Institute of Language, Brain \& Behaviour.

Notes Apple iPod Touch ${ }^{\circledR}$ and Apple iPad ${ }^{\circledR}$ are registered trademarks of the Apple Corporation, Cupertino California, www.apple.com

Proloquo2 $\mathrm{Go}^{\mathbb{}}{ }^{\mathrm{B}}$ is a registered trademark of AssistiveWare B.V., Amsterdam the Netherlands, www.assistiveware.com

\section{Compliance with Ethics Guidelines}

Conflict of Interest Jeff Sigafoos, Mark F. O'Reilly, Giulio E. Lancioni, and Dean Sutherland declare that they have no conflict of interest.

Human and Animal Rights and Informed Consent This article does not contain any studies with human or animal subjects performed by any of the authors.

\section{References}

Papers of particular interest, published recently, have been highlighted as:

- Of importance

•• Of major importance

1. Beukelman DR, Mirenda P. Augmentative and alternative communication: supporting children and adults with complex communication needs. 4th ed. Baltimore: Paul H. Brookes Publishing Co; 2012.

2. Johnston SS, Reichle J, Feeley KM, Jones EA. AAC strategies for individuals with moderate to severe disabilities. Baltimore: Paul $\mathrm{H}$. Brookes Publishing Co.; 2012.

3. Lancioni GE, Sigafoos J, O'Reilly MF, Singh NN. Assistive technology interventions for individuals with severe/profound and multiple disabilities. New York: Springer; 2013.

4. Lloyd LL, Fuller DR, Arvidson HH, editors. Augmentative and alternative communication: a handbook of principles and practices. Boston: Allyn \& Bacon; 1997.

5. Wendt O, Lloyd LL, Quist RW, editors. Assistive technology: principles and applications for communication disorders and special education. London: Emerald; 2011.

6. Osterling J, Dawson G, McPartland J. Autism. In: Walker C, Roberts MC, editors. Handbook of clinical child psychology. 5th ed. New York: Wiley; 2001. p. 432-52.

7. American Psychiatric Association. Diagnostic and statistical manual of mental disorders. 5th ed. Washington, DC: Author; 2013.

8. Gernsbacher MA, Dawson M, Goldsmith HH. Three reasons not to believe in an autism epidemic. Curr Dir Psychol Sci. 2005;14:55-8.

9. Centers for Disease Control and Prevention. Identified prevalence of autism spectrum disorders. Retrieved from http://www.cdc.gov/ ncbddd/autism/data.html, October 17, 2013.

10. Freitag CM. The genetics of autistic disorders and its clinical relevance: a review of the literature. Mol Psychiatry. 2007;12:2 22. doi:10.1038/sj.mp.4001896. PMID 17033636.

11. Fitzer A, Sturmey P, editors. Language and autism: applied behavior analysis, evidence and practice. Austin: Pro-Ed; 2009.

12. Mirenda P, Iacono T, editors. Autism spectrum disorders and AAC. Baltimore: Paul H. Brookes Publishing Co.; 2009.

13. Sennott S, Bowker A. Autism, AAC, and Prologuo2Go. Perspect Augmentative Altern Commun. 2009;18:137-45.

14. Mirenda P. Promising interventions in AAC for individuals with autism spectrum disorders. Perspect Augmentative Altern Commun. 2009;18:112-3. 
15. Achmadi D, Kagohara DM, van der Meer L, O'reilly MF, Lancioni GE, Sutherland D, et al. Teaching advanced operation of an iPadbased speech-generating device to two students with autism spectrum disorders. Res Autism Spectr Disord. 2012;6:1258-64. The first study to demonstrate effective procedures for teaching children with ASD perform advanced operations with an iPad®-based speech-generating device (i.e., turning on the device and navigating to the correct screen page).

16. Kagohara DM, van der Meer L, Achmadi D, Green VA, O'Reilly MF, Lancioni GE, et al. Teaching picture naming to two adolescents with autism spectrum disorders using systematic instruction and speech-generating devices. Res Autism Spectr Disord. 2012;6:1224-33. This study demonstrated effective procedures for teaching two adolescents with ASD to use an iPad®-based speech-generating device for an academic picture-naming communication skill. Prior studies had only focused on teaching requesting.

17. Kagohara DM, van der Meer L, Achmadi D, Green VA, O’Reilly MF, Mulloy A, et al. Behavioral intervention promotes successful use of an iPod-based communication device by an adolescent with autism. Clin Case Stud. 2010;9:328-38. This study demonstrated effective procedures for teaching an adolescent with ASD to successfully activate an iPad®-based speech-generating device. The important contribution here is that the adolescent initially had difficulty activating the device properly.

18. Sigafoos J, Lancioni GE, O'Reilly MF, Achmadi D, Stevens M, Roche L, et al. Teaching two boys with autism spectrum disorder to request the continuation of toy play using an iPad-based speechgenerating device. Res Autism Spectr Disord. 2013;7:923-30. This study demonstrated effective procedures for teaching two young

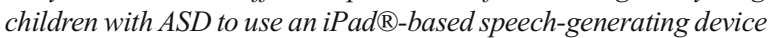
for a new type of requesting skill, that is requesting continuation of toy play.

19.• van der Meer L, Kagohara DM, Achmadi D, Green VA, Herrington C, Sigafoos J, et al. Teaching functional use of an iPod-based speech-generating device to individuals with developmental disabilities. J Spec Educ Technol. 2011;26:1-11. This is the first study to make use of $i P o d \AA / i P a d \circledR$ technology and Proloquo $2 G o \circledR$ software as a speech-generating device.

20. van der Meer L, Sigafoos J, Sutherland D, McLay L, Lang R, Lancioni GE, O'Reilly MF, Marschik PB. Preference-enhanced communication intervention and development of social communicative functions in a child with autism spectrum disorder. Clin Case Stud. 2013. doi:10.1177/1534650113508221 This study provided preliminary evidence to suggest that children might perform better on communication tasks when they use their preferred AAC option.

21. Kennedy CH. Single-case designs for educational research. Boston: Allyn \& Bacon; 2005

22. Duker P, Didden R, Sigafoos J. One-to-one training: instructional procedures for learners with developmental disabilities. Austin: Pro-Ed; 2004.

23. Mirenda P. Toward functional augmentative and alternative communication for students with autism: manual signs, graphic symbols, and voice output communication aids. Lang Speech Hear Serv Schools. 2003;34:203-16.

24. Bondy A, Frost L. The picture exchange communication system: clinical and research applications. In: Mirenda P, Iacono T, editors. Autism spectrum disorders and AAC. Baltimore: Paul H. Brookes Publishing Co.; 2009. p. 279-302.

25. Sundberg ML. Selecting a response form for nonverbal persons: facilitated communication, pointing systems, or sign language? Anal Verbal Behav. 1993;11:99-116.

26. Wendt $\mathrm{O}$. Research on the use of manual signs and graphic symbols in autism spectrum disorders. In: Mirenda P, Iacono T, editors. Autism spectrum disorders and AAC. Baltimore: Paul H. Brookes Publishing Co.; 2009. p. 83-139.
27. Sigafoos J, Drasgow E, Schlosser RW. Strategies for beginning communicators. In: Schlosser RW, editor. The efficacy of augmentative and alternative communication: toward evidence-based practice. Boston: Academic; 2003. p. 323-46.

28. Schlosser RW. Selecting graphic symbols for an initial request lexicon. In: Schlosser RW, editor. The efficacy of augmentative and alternative communication: toward evidence-based practice. Boston: Academic; 2003. p. 347-402.

29. Flippin M, Reszka S, Watson L. Effectiveness of the Picture Exchange Communication System (PECS) on communication and speech for children with autism spectrum disorders: a meta analysis. Am J Speech-Lang Pathol. 2010;19:178-95.

30. Lancioni GE, O'Reilly MF, Cuvo A, Singh NN, Sigafoos J, Didden R. PECS and VOCAs to enable students with developmental disabilities to make requests: an overview of the literature. Res Dev Disabil. 2007;28:468-88.

31. van der Meer L, Rispoli M. Communication interventions involving speech-generating devices for children with autism: a review of the literature. Dev Neurorehabil. 2010;13:294-306.

32.• Boesch MC, Wendt O, Subramanian A, Hsu N. Comparative efficacy of the Picture Exchange Communication Systems (PECS) versus a speech-generating device: effects on requesting skills. Res Autism Spectr Disord. 2013;7:480-93. This is an important comparison study showing that both PECS and a speechgenerating device can be taught simultaneously to children with ASD. Differences in acquisition rates were observed.

33.• Boesch MC, Wendt O, Subramanian A, Hsu N. Comparative efficacy of the Picture Exchange Communication Systems (PECS) versus a speech-generating device: effects on socialcommunicative skills and speech development. Augmentative Altern Commun. 2013;29:197-209. An important replication to the study by Boesch et al. [32•], which provides further evidence of simultaneous learning, yet differing acquisition rates, when teaching PECS versus a speech-generating device.

34.• Flores M, Musgrive K, Renner S, Hinton V, Strozier S, Franklin S, et al. A comparison of communication using the Apple iPad and a picture-based system. Augmentative Altern Commun. 2012;28:74 84. Another important comparison between PECS and an iPad®based speech-generating device, showing that both systems were generally learned with comparable ease.

35.• Lorah ER, Tincani M, Dodge J, Gilroy S, Hickey A, Hantula D. Evaluating picture exchange and the iPad as a speech generating device to teaching communication to young children with autism. J Dev Phys Disabil. 2013. doi:10.1007/s10882-013-9337-1. Another important comparison between PECS and an iPad®-based speechgenerating device, showing that four of the five children preferred to

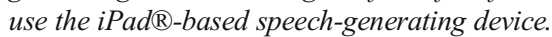

36.• van der Meer L, Didden R, Sutherland D, O'Reilly MF, Lancioni GE, Sigafoos J. Comparing three augmentative and alternative communication modes for children with developmental disabilities. J Dev Phys Disabil. 2012;24:45168. The first study to compare the use of three AAC options, that is manual signs, picture exchange and speechgenerating devices. Participants generally learned the picture exchange and speech-generating device options quicker and most showed a preference for the speech-generating device.

37.• van der Meer L, Kagohara D, Achmadi D, O’Reilly MF, Lancioni GE, Sutherland D, et al. Speech-generating devices versus manual signing for children with developmental disabilities. Res Dev Disabil. 2012;33:1658-69. The first study to compare the use of manual signs versus speech-generating devices. Participants learned the speech-generating device option quicker and most showed a preference for the speech-generating device.

38. van der Meer L, Kagohara D, Roche L, Sutherland D, Balandin S, Green VA, O'Reilly MF, Lancioni GE, Marschik PB, Sigafoos J. 
Teaching multi-step requesting and social communication to two children with autism spectrum disorders with three AAC options. Augmentative Altern Commun. 2013;29:222-234. An important study that extended existing research on teaching requesting, by aiming to teach a multi-step requesting sequence. The sequence was unique in that it included social communication and not just requesting skills.

39.• van der Meer L, Sutherland D, O'Reilly MF, Lancioni GE, Sigafoos J. A further comparison of manual signing, picture exchange, and speech-generating devices as communication modes for children with autism spectrum disorders. Res Autism Spectr Disord. 2012;6:1247-57. An important replication of the van der Meer et al. study [36*0] that compared the use of three AAC options, that is manual signs, picture exchange and speechgenerating devices. The results were consistent with van der Meer et al. [36॰०].

40. van der Meer L, Sigafoos J, O'Reilly MF, Lancioni GE. Assessing preferences for AAC options in communication interventions for individuals with developmental disabilities: a review of the literature. Res Dev Disabil. 2011;32:1422-31. 